\title{
Comparative Study of Essential Oils Extracted from Biebersteinia multifida DC Using Hydro-distillation, Microwave and Solvent Extraction \\ P Feyzi $^{1}$, T Ahmadzadeh sani ${ }^{2}$, P Alesheikh ${ }^{2}$, H Kamali $^{3}$, A Mohammadi ${ }^{1}$
}

\begin{abstract}
Objective: Biebersteinia multifida DC is from Geraniaceae family and it is used for the treatment of skeletonmuscle disorders and rehabilitating bone fractures. In this study, three extraction methods were applied for a comparative investigation about essential oils of Biebersteinia multifida DC.

Methods: three extraction methods such as hydro-distillation, solvent and microwave extractions were used for extraction of essential oils and then they were analyzed with GC-MS.

Results: Microwave extraction efficiency was 1.41 and 1.52 times higher than Hydro-distillation and solvent extraction. The extraction time was 72 h, $360 \mathrm{~min}$ and $98.60 \mathrm{~min}$ for solvent extraction, hydro-distillation and microwave respectively. Essential oils were analyzed with GC-MS and the results showed 38 compounds constituting $83.6,90.47$ and $88.42 \%$ of the total oils. $\beta$-farnesene and Hexadecanoic acid are same compounds in each three methods and the major compounds were different in three methods, major compounds in hydrodistillation method were (E)-Nerolidol (31.45\%), phytol (17.1 \%) and Hexadecanoic acid (11.84\%), major compounds via Microwave method were (E)-Nerolidol (28.4\%), n-Heptacosane (17.36\%), n-Docosane (12.97\%) and 6,10,14-trimethyl-2-pentadecanone (10.38\%), major compounds via solvent extraction method were
\end{abstract} Nonacosane (38.62\%), Mandenol (17.17\%) and n-Heptacosane (10.23\%).

Conclusion: the results of this study showed that the compounds in essential oils are dependent on the extraction way, also the results demonstrated quality of the essential oil, chemical compositions, yield efficiency and cost the operation microwave extraction was superior in extraction time and saving energy.

Keywords: Biebersteinia multifida, essential oils, hydro-distillation, solvent extraction, microwave extraction.

From: ${ }^{1}$ Natural Products and Medicinal Plants Research Center, North Khorasan University of Medical Sciences, Bojnurd, Iran, ${ }^{2}$ School of Pharmacy, Mashhad University of Medical Sciences, Mashhad, Iran, ${ }^{3}$ Targeted Drug Delivery Research Center, Mashhad University of Medical Sciences, Mashhad, Iran.

Correspondence: Dr A Mohammadi, Natural Products and Medicinal Plants Research Center

North Khorasan University of Medical Sciences, Bojnurd Iran

Email: Ameneh.mohamadi@yahoo.com

West Indian Med J

DOI: 10.7727.wimj.2016.245 


\section{INTRODUCTION}

Biebersteinia is a genus from Geraniaceae family, and one of endemic species in Iran is Biebersteinia multifida DC that in Persian is called Adamak (1).This plant is used for the treatment of skeleton-muscle disorders and rehabilitating bone fractures (2). Also the analgesic activity was shown from roots of plant (3). The anti-inflammatory and antinociceptive effects from roots of Biebersteinia multifida have been shown (3). Biebersteinia multifida DC Can reduce the level of Cholesterol (4). From this plant, alkaloids (5), flavonoids (6), essential oil and polysaccharides were isolated (7). Essential oils are natural products obtained from plants and they are found in medicinal plants and they are used for medicinal, fragrances, flavors and insect repellents purposes (8).

Many methods can be used for extraction of essential oils such as Steam distillation, hydro-distillation, Supercritical fluid extraction, solvent extraction and direct thermal desorption (9). The steam and hydro-distillation methods are traditional and simple techniques for essential oils but they have some problems such as chemical modifications of the oil compounds by temperatures and a loss of volatile compounds (10). Solvent extraction method overcomes the problems of hydro-distillation, but it has the major disadvantage; a product with solvent and a loss of the volatile components are the result of this method (11). Microwave extraction is affected by duration of microwave radiation, power of microwave, type of solvent, particle size of sample, temperature (12). The advantage of microwave method is for quicker times of extraction. Also this method is safe and cheap for extracting essential oil and does not require samples devoid of water (13). So the purpose of this work was to study the components of essential oil from Biebersteinia multifida DC obtained by microwave-assisted hydro-distillation, as compared with the normal hydro-distillation and solvent extraction. 


\section{MATERIALS AND METHODS}

\section{Materials}

N-hexanol (99.6\%, Merck), Hexadecanoic acid (76119, Fluka), Nerolidol (18143, analytical standard, Fluka), Phytol (W502200, $\geq 97 \%$, Sigma Aldrich) and 6, 10, 14-trimethyl-2pentadecanone (46195, Sigma Aldrich) were used as the four standards in essential oil of B. multifida.

\section{Preparation of $B$. multifida $D C$}

The aerial parts of plant were collected in April 2014 from Mountains in the North Khorasan Province of Iran. The plant was recognized by Natural products \& medical plants research center in North Khorasan (Iran). The voucher number of it was No: MP 57. The aerial parts of plant were dried in shade place (14).

\section{Hydro-distillation}

$50 \mathrm{~g}$ of dried plant was covered with $0.5 \mathrm{~L}$ of distilled water using a Clevenger. The extraction was done for $3 \mathrm{~h}$ and three times. The essential oil was dried with anhydrous sodium sulphate, and kept in refrigerator at $4{ }^{\circ} \mathrm{C}$ for GC-MS analysis (15).

\section{Solvent extraction}

$50 \mathrm{~g}$ of dried plant was macerated in $0.5 \mathrm{~L}$ of hexan solvent at room temperature for $48 \mathrm{~h}$. Removal of the solvent under vacuum at $40{ }^{\circ} \mathrm{C}$ gave the crude extract (16).

\section{Microwave Extraction}

Microwave Extraction was performed at atmospheric pressure with $2450 \mathrm{MHz}$ using a household microwave oven; which was mechanically modified to perform the hydro-distillation .Output power of Microwave was $800 \mathrm{~W}$ and input power of it was $1200 \mathrm{~W}$, the voltage supply of 
it was 230 volt and dimensions of the oven cavity were $206 \mathrm{~mm}(\mathrm{H}) \times 300 \mathrm{~mm}(\mathrm{~W}) \times 302 \mathrm{~mm}(\mathrm{D})$, with total capacity. Fifty gram of dried plant was mixed with $300 \mathrm{~mL}$ of distilled water (17). The condensation was done with a column that cooled with water. Microwave Extraction was done at $1 \mathrm{~kW}$ for $100 \mathrm{~min}$ in atmospheric pressure. Experiment was done triplicate and the essential oil was kept in a refrigerator at $4{ }^{\circ} \mathrm{C}$ to GC-MS analysis. The extraction yield (Y) was determined using Eq. (1).

$Y=\frac{\text { Total mass of essential oil with Microwave extraction method }}{\text { Total mass of essential oil with Hydrodistillation method }}$

\section{GC-FID analysis}

GC-FID analysis was done with a Schimadzu system by DB-5 column $(30 \mathrm{~m}, 0.25 \mathrm{~mm}, 0.25$ $\mu \mathrm{m})$. Helium with flow rate $0.9 \mathrm{~mL} / \mathrm{min}$ was used as the carrier gas. Volume for sample injection was $2 \mu \mathrm{L}$. For obtain the calibration curves, several concentrations of Hexadecanoic acid, Phytol, 6, 10, 14-trimethyl-2-pentadecanone and Nerolidol were injected into the GC-FID and the amounts of them were obtained by calculating the area of the peaks divided by the area of $n$ hexanol (internal standard) (As/Ais) (18). The extraction yield (Y) was obtained with Eq. (2).

$\mathrm{Y}=\frac{\text { Total mass of four components in extracted sample in Bmultifidia }}{\text { Total mass of dried Bmultifida }}$

\section{GC/MS analysis}

This analysis was done with a Shimadzu-QP2010SE (70 eV ionization energy). Acquisition mass range was 35-300 and scan time was $0.5 \mathrm{~s} / \mathrm{scan}$. The retention indices were determined using by $\mathrm{N}$-alkanes as standard (19). The compounds were recognized by comparison of their retention indices with other studies and Nist \& Wiley libraries (20). 


\section{RESULTS}

Microwave extraction efficiency was 1.41 and 1.52 times higher than Hydro-distillation and solvent extraction methods respectively. The extraction time for solvent extraction was more than other methods; this time was $72 \mathrm{~h}$ for solvent extraction, $360 \mathrm{~min}$ for hydro-distillation and $98.60 \mathrm{~min}$ for microwave method, so microwave method is better than two other methods because this method can reduce the time of extraction. The gas chromatograms of the essential oils from three methods are presented in Figs 1-3. Chemical compositions and their amounts are shown in Table 1.

As shown in Table 1; 29, 13 and 12 compounds were identified from essential oil by Hydrodistillation, Microwave and solvent extraction methods and they represented $90.47 \%, 88.42 \%$, $83.6 \%$ of the total essential oils. Major components in essential oil of B. multifida DC with hydro-distillation method were Nerolidol (31.45\%), phytol (17.1\%) and Hexadecanoic acid with 11.84\%, major compounds via Microwave method were (E)-Nerolidol (28.4\%), n-Heptacosane (17.36\%), n-Docosane (12.97\%), 6,10,14-trimethyl-2-pentadecanone (10.38\%), Epizonaren (7.23\%) and major compounds via solvent extraction method were Nonacosane (38.62\%), Mandenol (17.17\%) and n-Heptacosane (10.23\%).

\section{DISCUSSION}

As it was shown in Table 1, oxygenated components such as (E)-Nerolidol, phytol and Hexadecanoic acid were dominated in Hydro-distillation method. Proportion of monoterpene hydrocarbons such as n-Heptacosane and n-Docosane were also higher than Hydro-distillation method. Proportion of oxygenated diterpene such as Mandenol was increased and monoterpene hydrocarbon n-Heptacosane was decreased in solvent extraction method. Nonacosane is main 
compound in solvent extraction method and it wasn't seen in two other methods. Nerolidol and phytol were deleted in solvent extraction method. As shown in table $1, \beta$-farnesene and Hexadecanoic acid are same compounds in each three methods; also Hexadecanoic acid obtained from Hydro-distillation method was higher than two other methods. Five compounds such as $\beta$ farnesene, allo-aromadendrene, Hexadecanoic acid, Linoleic acid and Mandenol are common in two methods Hydro-distillation and solvent extraction methods. Ten compounds are similar in Hydro-distillation and microwave methods. Also three compounds such as (E)- $\beta$-farnesene, Hexadecanoic acid and n-Heptacosane are similar in microwave and solvent extraction methods. Four compounds such as 6, 10, 14-trimethyl 1-2-pentadecane, Nerolidol, Phytol and Hexadecanoic acid were potent antioxidants and main compounds in essential oil of B. multifida via Hydro-distillation (64.5\% from essential oil composition), where as they were $45.09 \%$ and $3.47 \%$ in total of essential oil composition via microwave and solvent extraction methods. Among compounds, Nerolidol was dominating compound in Hydro-distillation method that was a sesquiterpene which exhibited antileishmanial (21), antineoplastic (22) and antioxidant activity (23). Phytol is a diterpene with an unsaturated hydroxyl group demonstrates high level of antioxidant activities (24). Hexadecanoic acid can scavenge free radicals and it is a Fatty acid compound (24). There are some studies on essential oil of B. multifida DC; in one study, 6, 1, 14-trimethyl-2-pentadecanone and alpha-Pinene were the major components and in another research phytol, nerolidol, hexadecanoic acid and 6, 10, 14-trimethyl-2-pentadecanone were dominating compounds in essential oil of Biebersteinia multifida DC by hydro-distillation method (25-26). In another research, by using supercritical carbon dioxide method, four compounds contain $91.74 \%$ of the B. multifida essential oil (27). 


\section{CONCLUSION}

The results demonstrated that chemical compositions of essential oils are dependent to the extraction methods and also chemical compounds, yield efficiency. The efficiency of essential oil in B. multifida $D C$ was increased and the time extraction was decreased by microwave method. Also cost the microwave extraction was superior in saving time and energy. 


\section{REFERENCES}

1. Imani M. Herbarium of North Khorasan province, 1st ed., North Khorasan University of medical sciences press, Bojnurd; 2012: 255-256.

2. Amin G. Popular medicinal plant of Iran (In Persian), Research Institute of Medicinal Plants, Tehran, Iran; 1991: 33-35.

3. Farsam H, Amanlou M, Dehpour AR, Jahaniani F. Antiinflammatory and analgesic activity of Biebersteinian multifida DC root extract. J Ethnopharmacol 2000; 71: 443447.

4. Khakpour Sh, Akhlaghdoust M, Naimi S, Mirlohi MJ, Abedian M, Seyed-Forootan NS et al. Effect of Biebersteinia Multifida DC. Root Extract on Cholesterol in Mice. Zahedan J Res Med Sci 2013; 15: 49-51.

5. Kurbanov D, Zharekeev BK. A study of the alkaloids of Biebersteinia multifida and Peganum harmala from Karakalpak-ASSR. J. Khimija Prirodnykh Soyedineniy 1974; 5: 685-686.

6. Omurkamzinova VB, Maurel ND, Bikbulatova TN. Biebersteinia multifida flavonoids Khimiya Prirodnykh Soedinenii, J. Khimija Prirodnykh Soyedineniy 1991; 5: 720-721.

7. Arifkhodzhaev AO, Rakhimov DA. Polysaccharides of saponinbearing plants. IV. Structure of glucans A, B, and C of Biebersteinia multifida, J. Chem. Nat. Compd 1993; 29: 151-153.

8. Weiss EA. Essential Oil Crops, CAB International, USA. Saint-Ruffine; 1997: 3.

9. Poucher WA. Perfumes, Cosmetics and Soaps. Chapman and Hall Ltd. USA; 1974: 2237. 
10. Demorais S, Facundo V, Bertini L, Cavalcanti E, Anjosjunior J, Ferreira S et al. Chemical composition and larvicidal activity of essential oils from Piper species. Biochem. Syst. Ecol 2007; 35: 670-675.

11. Metherel AH, Taha AY, Izadi H, Stark KD. The application of ultrasound energy to increase lipid extraction throughput of solid matrix samples (flaxseed). Prostag. Leukot. Ess 2009; 81: 417-423.

12. Karakaya S, El SN, Karagözlü N, Sahin S. Antioxidant and antimicrobial activities of essential oils obtained from oregano (Origanum vulgare ssp. hirtum) by using different extraction methods. J. Med. Food 2011; 14(6): 645-652.

13. Chemat F, Lucchesi M, Smadja J, Favretto L, Colnaghi G, Visinoni F. Microwave accelerated steam distillation of essential oil from lavender: A rapid, clean and environmentally friendly approach. Anal. Chim. Acta 2006; 555: 157-160.

14. Sahena F, Zaidul ISM, Jinap S, Karim AA, Abbas KA, Norulaini NAN, et al. Application of supercritical CO2 in lipid extraction - A review. J. Food Eng 2009; 95: 240-253.

15. Saei-dehkordi S, Khalighi-sigaroodi F, Pirali-kheirabadi K, Saei-dehkordi S, Alimardaninaghani F, Fallah A. Chemical composition, antioxidative capacity and antimicrobial activity of Zeravschaina membranacea (boiss.) pimenov essential oil. J. Food Saf 2014; 34: 87-94.

16. Prachayasittikul S, Buraparuangsang P, Worachartcheewan A, Isarankura-Na-Ayudhya C, Ruchirawat S, Prachayasittikul V. Antimicrobial and antioxidative activities of bioactive constituents from Hydnophytum formicarum Jack. Molecules 2008; 13: 904 21. 
17. Ferhat MA, Meklati BY, Smadja J, Chemat F. An improved microwave Clevenger apparatus for distillation of essential oils from orange peel. J. Chromatogr A 2006; 1112: $121-126$.

18. Kamali H, Jalilvand MR, Aminimoghadamfarouj N. Pressurized fluid extraction of essential oil from Lavandula hybrida using a modified supercritical fluid extractor and a central composite design for optimization. J. Sep. Sci 2012; 35:1479-1485.

19. Smith R M. Extractions with superheated water. J. Chromatogr A 2002; 975: 31-46.

20. Adams RP. Identification of essential oil components by gas chromatography/ quadrupole mass spectroscopy, Allured Publishing Corporation, Carol Stream, 2001; 455.

21. Arruda DC, D'Aledandri FL, Katzin AM, Uliana SRB. Antileishmanial activity of the terpene nerolidol. Antimicrob. Agents Chemother 2005; 49: 1679-1687.

22. Wattenberg LW. Inhibition of azoxymethane-induced neoplasia of the largebowel by 3hydroxy-3,7,11-trimethyl-1,6,10- dodecatriene (nerolidol). Car-cinogenesis 1991; 12: $121-151$.

23. Keawsa-Ard S, Liawruangrath B, Liawruangrath S, Teerawutgulrag A, Pyne SG. Chemical constituents and antioxidant and biological activities of the essential oil from leaves of Solanum spirale. Nat. Prod. Commun 2012; 7: 955-958.

24. Kumar PP, Kumaravel S, Lalitha C. Screening of antioxidant activity, total phenolics and GC-MS study of Vitex negundo. Afr. J. Biochem. Res 2010; 4:191-195.

25. Akhlaghi H, Shafaghat A, Mohammadhosseini M. Chemical Composition of the Essential Oil from Leaves of Biebersteinia multifida DC. Growing Wild in Iran. J. Essent. Oil Bear. Plants 2009; 12 (3):365 - 368. 
26. Javidnia K, Miri R, Soltani M, Khosravi A.R. Essential Oil Composition of Biebersteinia multifida DC. (Biebersteiniaceae) from Iran. J. Essent. Oil Res 2010; 22, 6: 611-612.

27. Kamali H, Golmakani E, Golshan A, Mohammadi A, Ahmadzadeh Sani T. Optimization of ethanol modified supercritical carbon dioxide on theextract yield and antioxidant activity from Biebersteinia multifida DC. J. Supercrit. Fluids. 2014; 91:46-52. 
Table 1: Composition (\%) of B. multifida DC oils obtained by Hydro-distillation, solvent and Microwave extraction (the compounds were listed in order of elution time from a DB-5 column)

\begin{tabular}{|c|c|c|c|c|c|}
\hline No. & RI & Compound & $\begin{array}{r}\text { Chemical } \\
\text { constituents } \\
(\%) \text { of the } \\
\text { essential oil via } \\
\text { solvent } \\
\text { extraction }\end{array}$ & $\begin{array}{l}\text { Chemical } \\
\text { constituents }(\%) \\
\text { of the essential } \\
\text { oil via Hydro- } \\
\text { distillation }\end{array}$ & $\begin{array}{r}\text { Chemical } \\
\text { constituents } \\
\text { (\%) of the } \\
\text { essential oil via } \\
\text { Microwave } \\
\text { Extraction } \\
\end{array}$ \\
\hline 1 & 939 & $\alpha$-pinene & - & 0.29 & - \\
\hline 2 & 1096 & trans-sabinene hydrate & - & 1.58 & - \\
\hline 3 & 1099 & linalool & - & 0.55 & - \\
\hline 4 & 1143 & camphor & - & 0.41 & - \\
\hline 5 & 1418 & $\beta$-caryophyllene & - & 0.38 & - \\
\hline 6 & 1457 & (E)- $\beta$-farnesene ${ }^{a}$ & 0.9 & 0.23 & 0.66 \\
\hline 7 & 1462 & allo-aromadendrene ${ }^{b}$ & 1.64 & 0.78 & \\
\hline 8 & 1507 & $\alpha$-Farnesene ${ }^{d}$ & - & 0.56 & 0.61 \\
\hline 9 & 1512 & $\gamma$-Cadinene & - & 0.33 & \\
\hline 10 & 1522 & $\delta$-cadinene & - & 0.90 & - \\
\hline 11 & 1536 & $\alpha$-Cadinene & - & 0.68 & - \\
\hline 12 & 1552 & elemol & - & 1.26 & - \\
\hline 13 & 1565 & (E)-Nerolidol ${ }^{\mathrm{d}}$ & - & 31.45 & 28.4 \\
\hline 14 & 1583 & Caryophyllene oxide & - & 0.64 & \\
\hline 15 & 1594 & Viridiflorol $^{\mathrm{d}}$ & - & 0.58 & 0.37 \\
\hline 16 & 1610 & humulene epoxide II & - & 0.60 & - \\
\hline 17 & 1635 & $\tau$-Cadinol & - & 0.63 & \\
\hline 18 & 1656 & $\alpha$-Eudesmol & - & 0.74 & - \\
\hline 19 & 1671 & bulnesol & - & 2.24 & - \\
\hline 20 & 1688 & $\alpha$-Bisabolol & - & 3.81 & \\
\hline 21 & 1714 & (E)- Nerolidol acetate $\mathrm{d}$ & - & 0.28 & 1.29 \\
\hline 22 & 1727 & $(2 \mathrm{E}, 6 \mathrm{E})-$ Farnesol ${ }^{\mathrm{d}}$ & - & 5.5 & 2.36 \\
\hline 23 & 1759 & Myristic acid ${ }^{\mathrm{d}}$ & - & 1.23 & 0.48 \\
\hline 24 & 1845 & 6,10,14-trimethyl-2pentadecanone ${ }^{\mathrm{d}}$ & - & 3.66 & 10.38 \\
\hline 25 & 1917 & Farnesyl acetone & - & 0.29 & \\
\hline 26 & 1977 & Hexadecanoic acid ${ }^{\mathrm{a}}$ & 3.47 & 11.84 & 1.92 \\
\hline 27 & 2124 & Phytol $^{\mathrm{d}}$ & & 17.1 & 4.39 \\
\hline 28 & 2143 & Linoleic acid ${ }^{\mathrm{b}}$ & 3.49 & 0.4 & \\
\hline 29 & 2148 & Mandenol ${ }^{\mathrm{b}}$ & 17.17 & 1.53 & - \\
\hline 30 & 2162 & Ethyl linolenate & 1.59 & - & - \\
\hline 31 & 2312 & 10-cyclohexylnonadecane & 0.93 & - & - \\
\hline 32 & 2517 & Pentacosane & 1.4 & - & \\
\hline 33 & 2682 & $n-H e p t a c o s a n e^{c}$ & 10.23 & - & 17.36 \\
\hline 34 & 2791 & Octacosane & 2.09 & - & \\
\hline 35 & 2894 & Nonacosane & 38.62 & - & \\
\hline 36 & $-\infty$ & n-Docosane & - & - & 12.97 \\
\hline 37 & ----- & Epizonaren & - & - & 7.23 \\
\hline \multirow[t]{2}{*}{38} & 3138 & Vitamin E & 2.07 & - & \\
\hline & Total & & 83.6 & 90.47 & 88.42 \\
\hline
\end{tabular}

a) Similar compounds in three methods

b) Similar compounds in solvent extraction and Hydro-distillation

c) Similar compounds in solvent extraction and Microwave Extraction

d) Similar compounds in Hydro-distillation and Microwave Extraction 
Feyzi et al

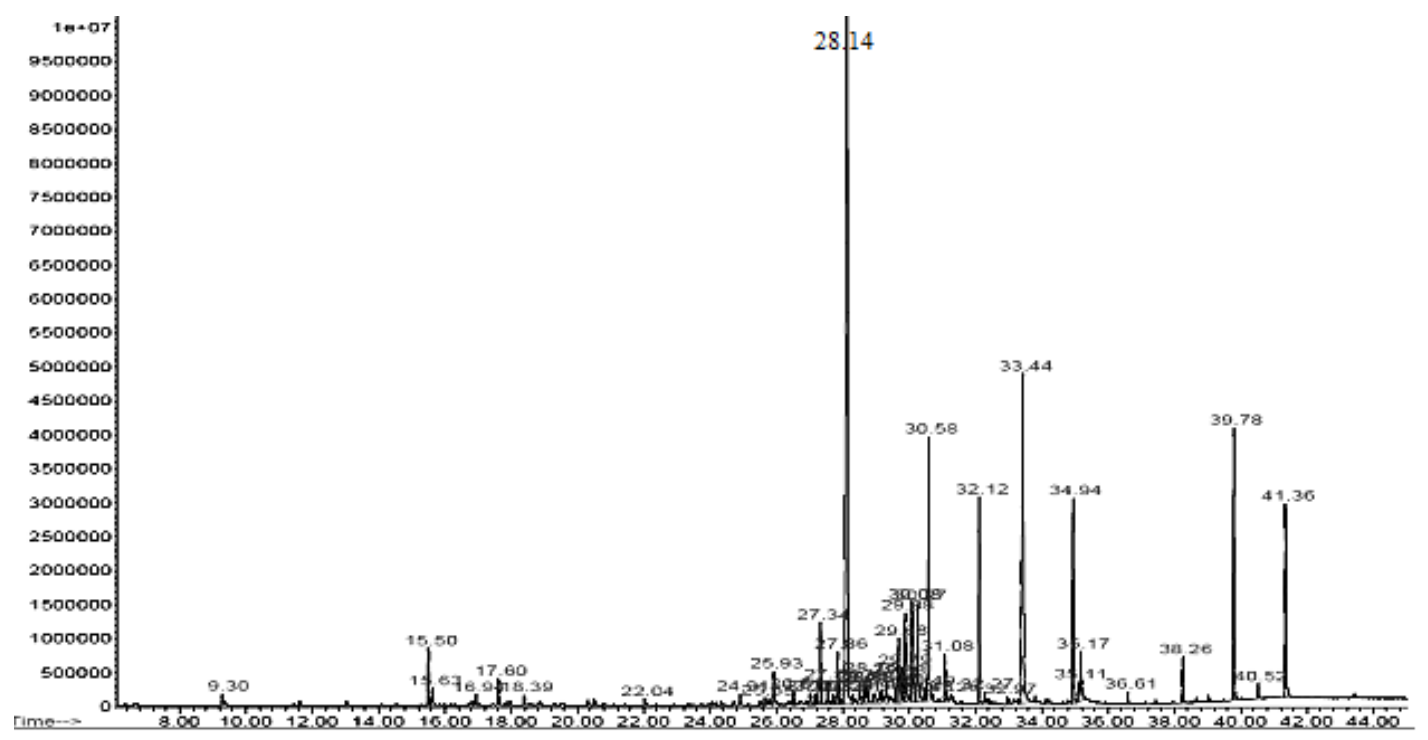

Fig 1: GC-Mass spectrum of essential oils of B. multifida DC extracted by Hydro-distillation method.

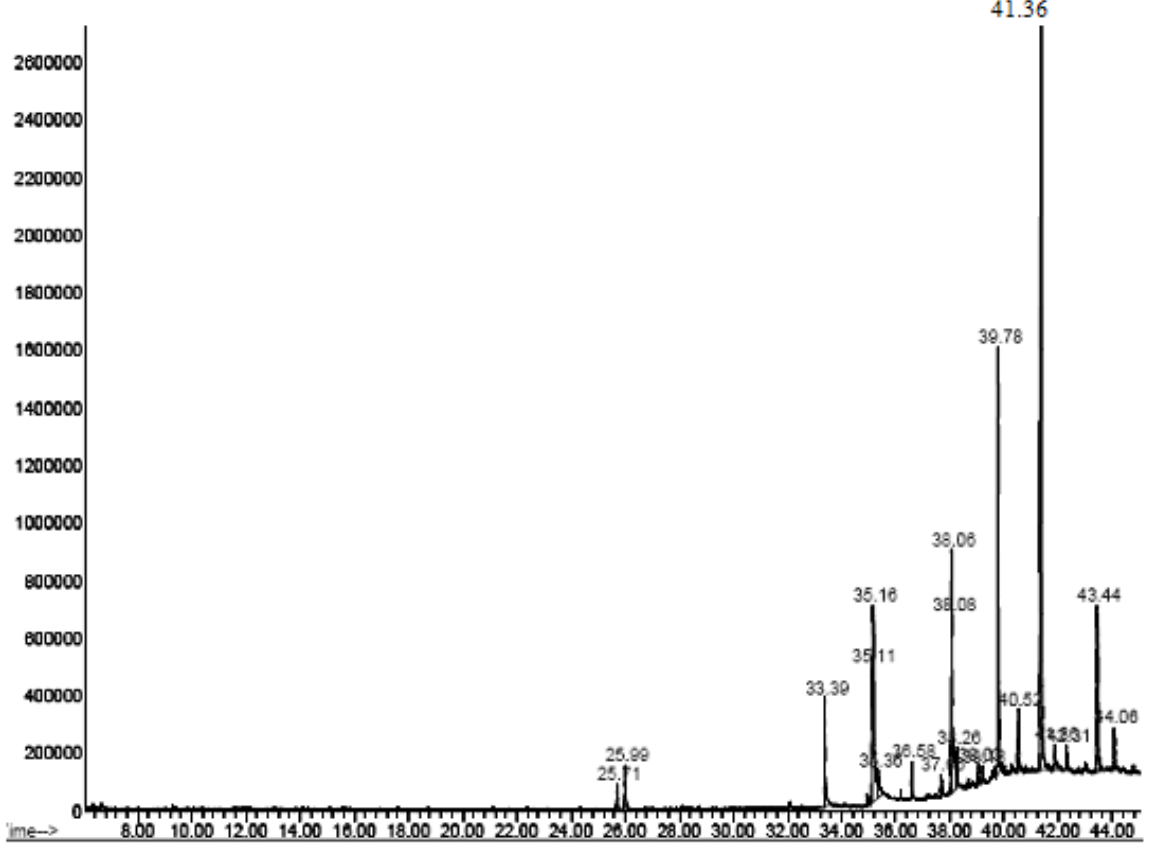

Fig 2: GC-Mass spectrum of essential oils of $B$. multifida $D C$ extracted by solvent extraction method 
Comparative Study of Essential oils extracted from Biebersteinia multifida DC

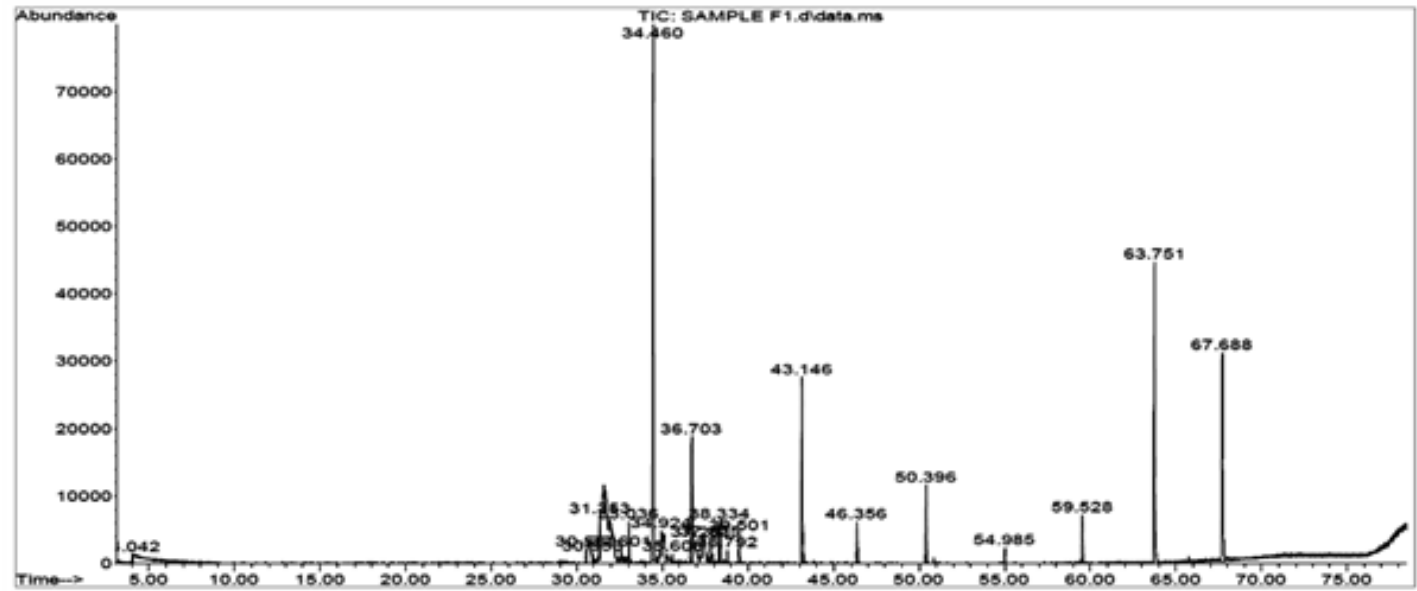

Fig 3: GC-Mass spectrum of essential oils of B. multifida DC extracted by microwave method, Microwave Extraction condition are: 900 watt and 100 min for power and time of extraction. 